\title{
Preparation of Magnetoliposomes with a Green, Low-Cost, Fast and Scalable Methodology and Activity Study against S. aureus and C. freundii Bacterial Strains
}

\author{
Rosangela M. F. da Costa e Silva, ${ }^{* a}$ Luciano R. S. Lara, ${ }^{a}$ Jorge L. López, ${ }^{b}$ \\ Ângela L. Andrade, ${ }^{c}$ Junnia A. C. Oliveira, ${ }^{d}$ Jacqueline A. Takahashi, ${ }^{a}$ \\ Henriete S. Vieira, ${ }^{a}$ Tulio Matencio, ${ }^{a}$ Humberto O. Stumpf ${ }^{a}$ and Rosana Z. Domingues ${ }^{a}$ \\ ${ }^{a}$ Departamento de Química, Universidade Federal de Minas Gerais (UFMG), \\ Av. Antonio Carlos 6627, Pampulha, 31270-901 Belo Horizonte-MG, Brazil \\ ${ }^{b}$ Centro de Ciências Biológicas e da Natureza (CCBN), Universidade Federal do Acre (UFAC), \\ Rodovia BR 364, km 04, s/n, Distrito Industrial, 69915-900 Rio Branco-AC, Brazil \\ ${ }^{c}$ Departamento de Química, Universidade Federal de Ouro Preto (UFOP), Morro do Cruzeiro, \\ 35400-000 Ouro Preto-MG, Brazil \\ 'Instituto de Ciências Biológicas, Universidade Federal de Minas Gerais (UFMG), \\ Av. Antonio Carlos 6627, Pampulha, 31270-901 Belo Horizonte-MG, Brazil
}

\begin{abstract}
A novel, fast, low-cost and scalable methodology to prepare stable magnetoliposomes (MGLs), without the use of organic solvents, is described. The concept of the work is based on the dual use of soy lecithin associated to a new liposome preparation methodology. Soy lecithin was used to coat the nanoparticles of magnetite $\left(\mathrm{Fe}_{3} \mathrm{O}_{4} @\right.$ lecithin) and for encapsulation of $\mathrm{Fe}_{3} \mathrm{O}_{4} @$ lecithin (Lip- $\mathrm{Fe}_{3} \mathrm{O}_{4} @$ lecithin). Liposomes with size less than $160 \mathrm{~nm}$, polydispersity index of 0.25 and zeta potential of $-41 \mathrm{mV}$, were prepared with the use of autoclave and sonication. The liposomal formulations containing magnetite and stigmasterol $\left(\mathrm{Lip}-\mathrm{Fe}_{3} \mathrm{O}_{4} @\right.$ lecithin, Lip-Stigma and Lip-Stigma- $\mathrm{Fe}_{3} \mathrm{O}_{4} @$ lecithin) were shown to be promising for the application as antibacterial. The liposomal formulation and magnetite were characterized by the following techniques: conventional and high-resolution transmission electron microscopy (TEM/HRTEM), energy-filtered transmission electron microscopy (EFTEM), proton nuclear magnetic resonance ( ${ }^{1} \mathrm{H}$ NMR), Fourier transform infrared spectroscopy (FTIR), X-ray powder diffraction (XRPD), dynamic light scattering (DLS) and zeta potential. The Lip- $\mathrm{Fe}_{3} \mathrm{O}_{4} @$ lecithin had a minimum inhibitory concentration (MIC) of $8.4 \mu \mathrm{g} \mathrm{mL}^{-1}$ in the presence of 200 Oe magnetic field against $S$. aureus.
\end{abstract}

Keywords: soy lecithin, magnetite, liposomes, S. aureus, C. freundii

\section{Introduction}

The disordered use of antibiotics has increased the inefficiency of several classes of antibacterial agents in combating microorganisms called multiresistant. Such microorganisms are present in hospitals of large metropolises or even diverse environments of small communities. ${ }^{1-5}$ The Gram-positive bacterium Staphylococcus aureus is the leading cause of human bacterial infections worldwide, being endemic and readily resistant to antimicrobials. S. aureus is listed in the World Health Organization (WHO $)^{6}$ as one of the six pathogens

*e-mail: rosangela_ferreirafeliz@yahoo.com.br with priority II (high) in the development of new antibiotics. Regarding Gram-negative bacteria, the WHO warns of resistance to multiple antibiotics and the ability to transmit genetic material to other bacteria. An example of Gramnegative bacteria, Citrobacter freundii is a fecal coliform that resides in water, soils, and intestines of humans. ${ }^{7}$ Inorganic pharmaceuticals containing metal oxides may utilize different action mechanisms and can, therefore, be considered a viable alternative to traditional antibiotics. ${ }^{8}$ One option is the use of iron oxide magnetic nanoparticles (IOMNPs). IOMNPs have been extensively explored in several areas, such as nanocatalysis, ${ }^{9}$ hyperthermia, ${ }^{10}$ magnetic resonance imaging ${ }^{11}$ and cancer treatment. ${ }^{12}$ The properties of IOMNPs are suitable for a wide diversity of 
applications, such as high surface area and heat generation capacity by the application of an external magnetic field. ${ }^{9-13}$ Several studies on the antibacterial activity of IOMNPs, in particular the magnetite nanoparticles (NPs) are described in the literature. ${ }^{14-17}$ Limitations due to agglomeration and interactions with biological media have been overcome by coating the NPs with several classes of stabilizing agents. ${ }^{18-21}$ Another strategy to increase the interaction of NPs with biological media is encapsulation in liposomes, preparing so-called magnetoliposomes (MGLs). The encapsulation in liposomal vesicles permits reduced contact between drugs and healthy cells; as well as increased efficiency in traversing the diseased cell membrane to reach the target. ${ }^{18,22}$

In this paper, soy lecithin, a combination of phospholipids fromrenewablesources, was used tocoat $\mathrm{NPs}\left(\mathrm{Fe}_{3} \mathrm{O}_{4} @\right.$ lecithin) and then as liposome for encapsulating the $\mathrm{Fe}_{3} \mathrm{O}_{4} @$ lecithin. Two previous studies ${ }^{23,24}$ using soy lecithin as the coat of NPs have been described. However, none of the studies used lecithin as a liposome. The addition of the second step for encapsulation of $\mathrm{Fe}_{3} \mathrm{O}_{4} @$ lecithin was determinant to obtain more stable MGLs than $\mathrm{Fe}_{3} \mathrm{O}_{4} @$ lecithin in the aqueous medium. Another factor that distinguishes our paper from the previous publications is the order of addition of reagents. In our work, soy lecithin was added after the co-precipitation, reducing the possibility of encapsulation residuals of initial reagents in the soy lecithin clusters. Therefore, dual use of the soy lecithin biomimetic agent ${ }^{25}$ increased the interaction between $\mathrm{Fe}_{3} \mathrm{O}_{4}$ and liposome vesicles in the Lip- $\mathrm{Fe}_{3} \mathrm{O}_{4} @$ lecithin, creating new possibilities for the preparation of MGLs. Another enhancement was enabling the MGLs to be highly water-dispersive using a novel methodology that is fast, low-cost and scalable without the use of organic solvents, which were not previously described in the literature. Traditional methodologies such as film hydration ${ }^{26}$ and sonication ${ }^{27}$ require a lot of preparing time and the use of organic solvents to achieve small quantities of product. ${ }^{28}$ Subsequently, they are still subjected to a sterilization step. ${ }^{29}$ Therefore, a new methodology was proposed to prepare sterile liposomes. This methodology involves hydrating the soy lecithin in an autoclave at $120^{\circ} \mathrm{C}$ for $15 \mathrm{~min}$, cooling to $4{ }^{\circ} \mathrm{C}$, liposome size reduction, encapsulating stigmasterol and/or $\mathrm{Fe}_{3} \mathrm{O}_{4} @$ lecithin and using ultrasound tip. The use of an initial autoclave stage allows preparation of large amounts of the liposomes. The production is only limited by to the capacity of the autoclave equipment that can reach industrial scales. In addition, the influence of use of stigmasterol (Stigma), a molecule similar to cholesterol, was also investigated. ${ }^{28,29}$ The liposomes prepared were tested against $S$. aureus and $C$. freundii microorganisms in the presence of a magnetic field (MF41) of $200 \mathrm{Oe}, 315 \mathrm{kHz}$ and also in its absence at room temperature (WMF25) and at temperature of $41{ }^{\circ} \mathrm{C}(\mathrm{WMF} 41)$.

\section{Experimental}

\section{Materials}

Stigmasterol (Sigma-Aldrich Chemical Company, USA), soy lecithin (CRQ, Brazil), iron sulfate II ammoniacal hexahydrate (Vetec, Brazil), iron chloride III hexahydrate (Vetec, Brazil), $\mathrm{CDCl}_{3}$ (Sigma-Aldrich Chemical Company, USA), ammonium hydroxide PA (Synth, Brazil), sodium hydroxide PA (Synth, Brazil), citric acid (Synth, Brazil), brain heart infusion (BHI) agar (Kasvi, Brazil), BHI broth (Kasvi, Brazil) were used without any purification. The Gram-positive and Gram-negative bacteria used were Staphylococcus aureus (ATCC 29212), and Citrobacter freundii (ATCC 8090), respectively. The ultrapurified water was obtained by Milli-Q system (Millipore, Brazil).

\section{Preparation of the bare liposome (Lip)}

Bare liposomes were prepared by hydration of soy lecithin (100 $\left.\mathrm{mg} \mathrm{mL}^{-1}\right)$ in ultra-purified water. The autoclavable flask containing the components were autoclaved (CS Prismatec Autoclave, Brazil) for $15 \mathrm{~min}$ at $120{ }^{\circ} \mathrm{C}$. Bare liposomes were maintained at $4{ }^{\circ} \mathrm{C}$ for $24 \mathrm{~h}$. Then, the bare liposomes were sonicated on tip ultrasound (Disruptor Unique Model DES 500, Brazil) for reducing sizes. ${ }^{26,30}$ Standards of 4 cycles $\times 4$ min were performed with intervals of $1 \mathrm{~min}$ for each sequence, at $95 \%$ power $(500 \mathrm{~W})$. The temperature of sample was maintained below $75^{\circ} \mathrm{C}$. The sample was noted Lip.

\section{Synthesis of $\mathrm{Fe}_{3} \mathrm{O}_{4} @$ lecithin}

Magnetite coated with soy lecithin $\left(\mathrm{Fe}_{3} \mathrm{O}_{4} @\right.$ lecithin) was prepared in a one-pot reaction using the modified co-precipitation methodology of the literature. ${ }^{31,32}$ Briefly, in a two-neck round bottom flask, under nitrogen flow, $500 \mathrm{~mL}$ of ultra-purified and degassed water were mixed to $\mathrm{Fe}\left(\mathrm{NH}_{4}\right)_{2}\left(\mathrm{SO}_{4}\right)_{2} \cdot 6 \mathrm{H}_{2} \mathrm{O}(0.0459 \mathrm{~mol})$, and $\mathrm{FeCl}_{3} \cdot 6 \mathrm{H}_{2} \mathrm{O}$ $(0.08879 \mathrm{~mol})$. The solution was stirred for $5 \mathrm{~min}$ at room temperature. After that, $200 \mathrm{~mL}$ of $\mathrm{NH}_{4} \mathrm{OH}$ was added under stirring for synthesis of the nanoparticles magnetite $\left(\mathrm{Fe}_{3} \mathrm{O}_{4}\right)$ and stirred for additional $20 \mathrm{~min}$. Sequentially, $100 \mathrm{~mL}$ of Lip (100 mg mL $\mathrm{mL}^{-1}$ ) was added under constant stirring for $10 \mathrm{~min}$ in the bottom flask. The $\mathrm{Fe}_{3} \mathrm{O}_{4}$ coated by soy lecithin was washed with ultra-purified degassed 
water. ${ }^{31,33}$ The sample was denominated $\mathrm{Fe}_{3} \mathrm{O}_{4} @$ lecithin and was conditioned in Falcon tubes, lyophilized and stored at $0{ }^{\circ} \mathrm{C}$. The yield of this operation was $92 \%$.

\section{Preparation of liposome formulations}

Aliquots of $10 \mathrm{~mL}$ of the Lip were separated for stigmasterol and/or magnetite components incorporation. The liposomal preparations were named according to their composition: stigmasterol (Lip-Stigma), stigmasterol and coated magnetite (Lip-Stigma- $\mathrm{Fe}_{3} \mathrm{O}_{4} @$ lecithin), and the coated magnetite (Lip- $\mathrm{Fe}_{3} \mathrm{O}_{4} @$ lecithin). A bare liposomal formulation containing the phospholipid (Lip) was also prepared as standard sample. Lip, Lip-Stigma, Lip-Stigma$\mathrm{Fe}_{3} \mathrm{O}_{4} @$ lecithin, Lip- $\mathrm{Fe}_{3} \mathrm{O}_{4} @$ lecithin were submitted to the same ultrasound cycle defined previously. Then, the formulations were ultracentrifuged ${ }^{34}$ for $20 \mathrm{~min}$ at $10000 \times \mathrm{g}$ in Eppendorf model 5810R centrifuge (Germany). The supernatant was separated and the formulation resuspended in ultra-purified water. The procedure was performed until all unencapsulated components of Lip, Lip-Stigma, Lip-Stigma- $\mathrm{Fe}_{3} \mathrm{O}_{4} @$ lecithin and Lip- $\mathrm{Fe}_{3} \mathrm{O}_{4} @$ lecithin were removed from the formulations. The formulations were suspended in phosphate buffered saline (PBS buffer) at $\mathrm{pH} 7.3 \pm 0.1$, leading to the final concentrations (Table 1) determined by atomic absorption spectroscopy (AAS) and proton nuclear magnetic resonance ( $\left.{ }^{1} \mathrm{H} \mathrm{NMR}\right)$.

Table 1. Content of soy lecithin, stigmasterol and magnetite

\begin{tabular}{|c|c|c|c|}
\hline Sample & $\begin{array}{l}\text { Lecithin / } \\
\left(\mathrm{mg} \mathrm{mL}^{-1}\right)\end{array}$ & $\begin{array}{l}\text { Stigmasterol / } \\
\left(\mathrm{mg} \mathrm{mL}^{-1}\right)\end{array}$ & $\begin{array}{c}\mathrm{Fe}_{3} \mathrm{O}_{4} / \\
\left(\mathrm{mg} \mathrm{mL}^{-1}\right)\end{array}$ \\
\hline Lip & 92 & - & - \\
\hline Lip- $\mathrm{Fe}_{3} \mathrm{O}_{4} @$ lecithin & 92 & - & 7.0 \\
\hline Lip-Stigma & 92 & 39 & - \\
\hline Lip-Stigma- $\mathrm{Fe}_{3} \mathrm{O}_{4} @$ lecithin & 92 & 39 & 9.7 \\
\hline
\end{tabular}

\section{Characterization of $\mathrm{Fe}_{3} \mathrm{O}_{4} @$ lecithin and liposomes}

Zeta potential $(\zeta)$ was performed for $\mathrm{Fe}_{3} \mathrm{O}_{4} @$ lecithin, Lip, Lip-Stigma, Lip- $\mathrm{Fe}_{3} \mathrm{O}_{4} @ 1$ ecithin and Lip-Stigma- $\mathrm{Fe}_{3} \mathrm{O}_{4} @$ lecithin (Zetasizer Nano ZS equipment, United Kingdom) in triplicates at $25.0{ }^{\circ} \mathrm{C}$ for 14 days. The same apparatus was used for analyses of liposome size using dynamic light scattering (DLS). The samples were lyophilized in a Terroni Lyophilizer model LS 3000 (Brazil) for ${ }^{1} \mathrm{H}$ NMR, infrared spectroscopy technique (FTIR), X-ray powder diffraction (XRPD) and for magnetics measurements. The initial and final mass of all lyophilized samples were measured on analytical balance (Shimadzu, model AUW220D, Brazil). Crystallographic phases of $\mathrm{Fe}_{3} \mathrm{O}_{4} @$ lecithin, Lip- $\mathrm{Fe}_{3} \mathrm{O}_{4} @$ lecithin, Lip-Stigma- $\mathrm{Fe}_{3} \mathrm{O}_{4} @$ lecithin were characterized by XRPD, using Rigaku-Geigerflex equipment (Japan) and Siemens-D5000 diffractometer (Germany), with $\mathrm{CuK} \alpha$ radiation in the range of 5 to $80^{\circ}$ and $1^{\circ} \mathrm{min}^{-1}$. The iron oxide phase was determined by fitting (311) peak by Voigt function. ${ }^{35,36}$ FTIR (PerkinElmer FT-IR GX model, USA) were performed to evaluate the coating of $\mathrm{Fe}_{3} \mathrm{O}_{4} @$ lecithin, iron oxide phase and to verify the absence of hydrolysis of the esters or oxidation in Lip, Lip-Stigma, Lip- $\mathrm{Fe}_{3} \mathrm{O}_{4} @$ lecithin and Lip-Stigma- $\mathrm{Fe}_{3} \mathrm{O}_{4} @$ lecithin. The solids were homogenized in $\mathrm{KBr}(1 \% \mathrm{~m} / \mathrm{m})$ and disc-pressed. The FTIR spectra were recorded in transmittance mode in the 4000 to $400 \mathrm{~cm}^{-1}$ range. Morphologies, particle size distribution, and phases by micrographs were recorded on transmission electron microscope Tecnai G2-20 SuperTwin FEI, $200 \mathrm{kV}$ (USA). The samples were diluted in water and one drop was deposited on holey carbon- $\mathrm{Cu}, 300$ mesh, 50 micron screens. ${ }^{37}$ The micrographs were obtained in the conventional and high-resolution transmission electron microscopy (TEM/HRTEM) and energy-filtered transmission electron microscopy (EFTEM) modes. The mean diameter of $\mathrm{Fe}_{3} \mathrm{O}_{4}$ in the $\mathrm{Fe}_{3} \mathrm{O}_{4} @$ lecithin was calculated by the ImageJ software package. The HRTEM images were processed in the Digital Micrograph program in the fast Fourier transform mode (FFT) for determination of the interplanar spacing. ${ }^{38}$ Spectroscopic analyses of ${ }^{1} \mathrm{H}$ NMR were recorded on DPR 400 Bruker Avance II DRX 400 equipment (USA) operating at $400 \mathrm{MHz}$. This technique was used to determine phospholipids/steroids molar ratio of soy lecithin, stigmasterol in the Lip and Lip-Stigma and to verify the absence of phospholipid hydrolysis. The samples Lip and Lip-Stigma were lyophilized and solubilized in $\mathrm{CDCl}_{3}$. The hysteresis curves of $\mathrm{Fe}_{3} \mathrm{O}_{4} @$ lecithin and Lip- $\mathrm{Fe}_{3} \mathrm{O}_{4} @$ lecithin at $310 \mathrm{~K}$ were obtained on a SQUID (superconducting quantum interference device) Magnetometer Cryogenic S700X (Argentina) with magnetic field capacity up to 7 T. FAAS was used to determine iron content in $\mathrm{Fe}_{3} \mathrm{O}_{4} @$ lecithin, Lip- $\mathrm{Fe}_{3} \mathrm{O}_{4} @$ lecithin and Lip-Stigma- $\mathrm{Fe}_{3} \mathrm{O}_{4} @$ lecithin on a Hitachi-Z8200 spectrometer (Japan) coupled to a graphite furnace.

Biological activity without magnetic field at room temperature (WMF25), without magnetic field at $41 \pm 1{ }^{\circ} \mathrm{C}$ (WMF41) and with magnetic field at $41 \pm 1^{\circ} \mathrm{C}(\mathrm{MF} 41)$

Antibacterial activity of the liposomes was assayed by the agar dilution method. ${ }^{39}$ Bacteria S. aureus (ATCC 29213) and $C$. freundii (ATCC 8090) were individually inoculated in vials containing BHI broth and incubated in an oven at $37^{\circ} \mathrm{C}$ 
for $24 \mathrm{~h}$. Inoculum containing approximately $1 \times 10^{6}$ colony forming units (CFU) of each microorganism per $\mathrm{mL}$ of sterile water were prepared in sterile vials (InocSol). Liposomes samples described in Table 1 and InocSol were added to Eppendorfs containing BHI broth. The final concentrations of liposomes were presented in the Table 2 with total volume of the $1 \mathrm{~mL}$ per Eppendorf.

Table 2. Content of lecithin, stigmasterol and magnetite

\begin{tabular}{lccc}
\hline Sample & $\begin{array}{c}\text { Lecithin / } \\
\left(\mathrm{mg} \mathrm{mL}^{-1}\right)\end{array}$ & $\begin{array}{c}\text { Stigmasterol / } \\
\left(\mathrm{mg} \mathrm{mL}^{-1}\right)\end{array}$ & $\begin{array}{c}\mathrm{Fe}_{3} \mathrm{O}_{4} / \\
\left(\mathrm{mg} \mathrm{mL}^{-1}\right)\end{array}$ \\
\hline Lip-Fe $\mathrm{O}_{4} @$ lecithin1 & 0.80 & - & 0.059 \\
Lip-Fe $\mathrm{O}_{4} @$ lecithin2 & 0.11 & - & 0.0084 \\
Lip-Stigma1 & 0.80 & 0.32 & - \\
Lip-Stigma2 & 0.11 & 0.045 & - \\
Lip-Stigma-Fe $3 \mathrm{O}_{4} @$ lecithin1 & 0.80 & 0.32 & 0.081 \\
Lip-Stigma-Fe $\mathrm{O}_{4} @$ lecithin2 & 0.11 & 0.045 & 0.012 \\
\hline
\end{tabular}

Tests for $S$. aureus and C. freundii inhibition were done against the liposomes samples prepared under three different conditions: (i) $25^{\circ} \mathrm{C}$ for $30 \mathrm{~min}$ (WMF25); (ii) oven heating at $41 \pm 1{ }^{\circ} \mathrm{C}$ for $30 \mathrm{~min}$ (WMF41); and (iii) magnetic field for $30 \mathrm{~min}$ at $41 \pm 1{ }^{\circ} \mathrm{C}$ (MF41). The sample with number 2 was tested against $S$. aureus and C. freundii in the condition: (iii) magnetic field for $30 \mathrm{~min}$ at $41 \pm 1{ }^{\circ} \mathrm{C}$ (MF41). The liposome samples were diluted in BHI agar plates and maintained at $37^{\circ} \mathrm{C}$ for $24 \mathrm{~h}$. Then the CFUs were quantified. The procedure was performed in triplicate. Quantification of inhibition of bacterial growth was done according to the literature. ${ }^{39,40}$ Samples submitted to MF41 treatment were accompanied by a reference sample (no inoculum) of the same concentration and volume for temperature control. Samples $(1 \mathrm{~mL})$ were placed in the center of the three-turn coil with internal diameter of $3.2 \mathrm{~cm}$ and a magnetic field of $200 \mathrm{Oe}, 300 \mathrm{~A}$ and frequency of $315 \mathrm{kHz}$ (Easyheat Ambrell, models 0224 , USA) was applied for $30 \mathrm{~min}$. When the temperature reached about $41.8^{\circ} \mathrm{C}$, the equipment was switched off and restarted only when the temperature was below $40.5^{\circ} \mathrm{C}$. The total time of $30 \mathrm{~min}$ in the magnetic field did not consider the time required for the sample to be cooled so that the temperature did not reach values higher than $42{ }^{\circ} \mathrm{C}$. The samples were kept inside the coil throughout the treatment. The temperature variation in the reference sample was measured through a fiber optic thermometer (New Star 5kW RF Power Supply, Ameritherm, Inc., USA) located in the center of the Eppendorf (reference sample). The heat rate measurements were recorded by a Photon Control software TPMeter 10FTC-DIN-GT-HT.

\section{Results and Discussion}

The first step in preparing the MGLs involved the synthesis of magnetite through a modified co-precipitation method previously described ${ }^{31,32}$ and then the modification of its surface in a one-pot reaction is shown in Figure 1 (steps 1a, 1b and 2) to prepare $\mathrm{Fe}_{3} \mathrm{O}_{4} @$ lecithin.

(1b)
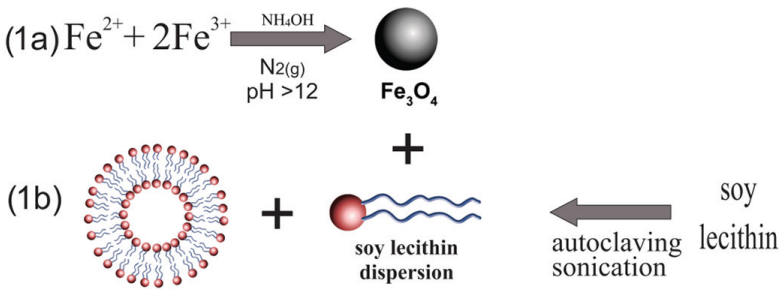

soy lecithin liposome

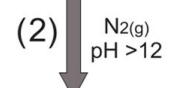

(3)
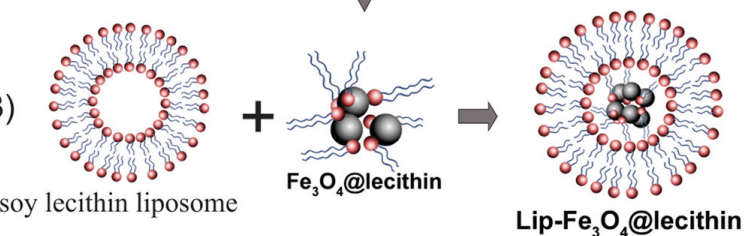

Figure 1. Preparation of magnetoliposomes.

\section{Characterization of $\mathrm{Fe}_{3} \mathrm{O}_{4} @$ lecithin}

The TEM image (Figure S1a, Supplementary Information (SI) section) of the $\mathrm{Fe}_{3} \mathrm{O}_{4} @$ lecithin shows the nanoclusters formation. ${ }^{9,23}$ NPs of the $\mathrm{Fe}_{3} \mathrm{O}_{4}$ in the $\mathrm{Fe}_{3} \mathrm{O}_{4} @$ lecithin (Figure S1b, SI section) have a mean size of $13 \mathrm{~nm}$. The magnetite phase of $\mathrm{Fe}_{3} \mathrm{O}_{4} @$ lecithin (Figure 2) was determined by X-ray powder diffraction (XRPD) according to JCPDS card 19-629. The mean diameter of $15 \mathrm{~nm}$ of the crystallite was determined by the Debye-Scherer equation. ${ }^{41,42}$ The structure determined was of cubic face centered (fcc) Fd-3m without deformation. The calculated net parameter was $a=8.41 \AA$ and the density was $5.18 \mathrm{~g} \mathrm{~cm}^{-3} .9,10$

The FTIR spectra for $\mathrm{Fe}_{3} \mathrm{O}_{4} @$ lecithin (Figure 3) show the vibration frequency related to the $\mathrm{Fe}-\mathrm{O}$ bond $\left(561 \mathrm{~cm}^{-1}\right)$ of magnetite and the spectra confirm the surface functionalization by soy lecithin of $\mathrm{Fe}_{3} \mathrm{O}_{4} @$ lecithin. Magnetite $(88 \pm 1 \% \mathrm{~m} / \mathrm{m})$ contents in $\mathrm{Fe}_{3} \mathrm{O}_{4} @$ lecithin were determined by AAS.

The saturation magnetization (Ms) of the $\mathrm{Fe}_{3} \mathrm{O}_{4} @$ lecithin

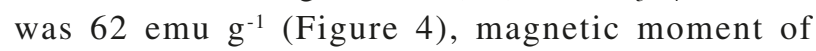
$\mu=1.86 \times 10^{-19} \mathrm{~J} \mathrm{~T}^{-1}$ and magnetic susceptibility at high fields was $0.96 \times 10^{-4} \mathrm{emu} \mathrm{g}^{-1}$ at $310 \mathrm{~K}$. The hysteresis curves were adjusted using the Fortran 90 program based on the Langevin model in the super paramagnetic region (equation S1, SI section). ${ }^{43}$ The average magnetic core 


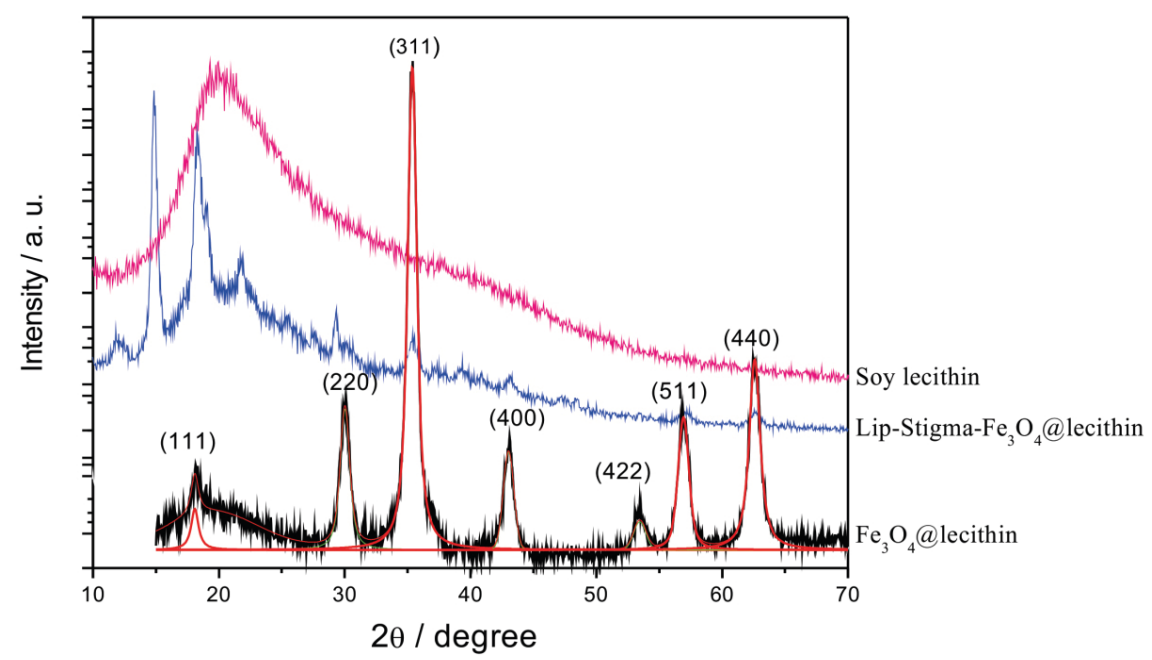

Figure 2. XRPD of soy lecithin, $\mathrm{Fe}_{3} \mathrm{O}_{4} @$ lecithin and Lip-Stigma- $\mathrm{Fe}_{3} \mathrm{O}_{4} @$ lecithin.

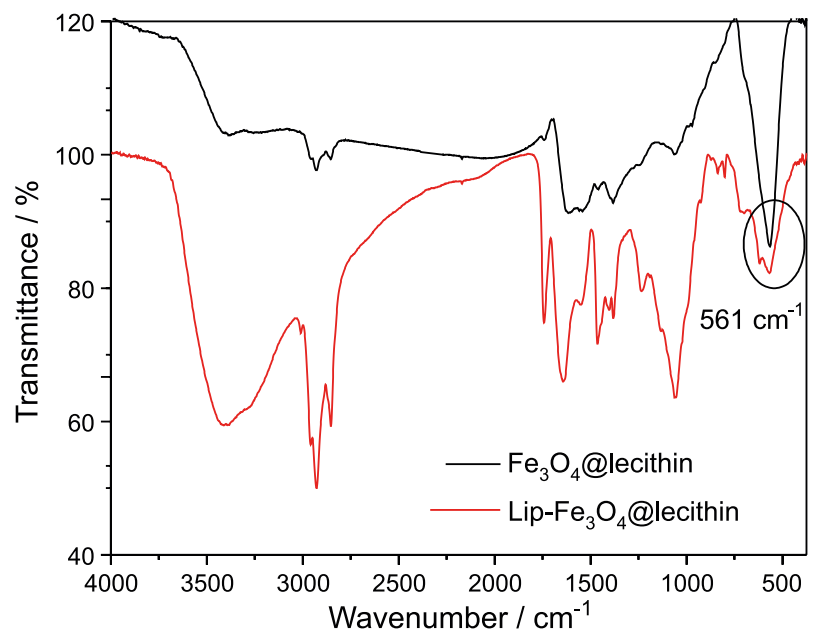

Figure 3. FTIR spectra of $\mathrm{Fe}_{3} \mathrm{O}_{4} @$ lecithin and Lip- $\mathrm{Fe}_{3} \mathrm{O}_{4} @$ lecithin.

diameter calculated using the Fortran 90 software program was $12.7 \pm 0.2 \mathrm{~nm}$ confirming the values determined by TEM and XRPD. This value is consistent with nanoparticle super paramagnetic behavior. ${ }^{40}$ The zeta potential $(\zeta)$ values found for $\mathrm{Fe}_{3} \mathrm{O}_{4} @$ lecithin were $-19 \pm 1 \mathrm{mV}$. The zeta potential $(\zeta)$ confirms the stability of NPs with high water-dispersion in an aqueous medium.

The second step in MGLs preparation involves the encapsulation of the stigmasterol (Lip-Stigma), of $\mathrm{Fe}_{3} \mathrm{O}_{4} @ 1$ ecithin (Lip- $\mathrm{Fe}_{3} \mathrm{O}_{4} @ 1$ ecithin) and encapsulation of the stigmasterol and $\mathrm{Fe}_{3} \mathrm{O}_{4} @$ lecithin (Lip-Stigma- $\mathrm{Fe}_{3} \mathrm{O}_{4} @$ lecithin) as shown in Figure 1 (step 3). The samples were compared to the bare liposome (Lip).

\section{Characterization of liposomes}

The liposome size, polydispersity index (PI), zeta potential $(\zeta), \mathrm{pH}$ and the FTIR of the liposomes (Table 1)

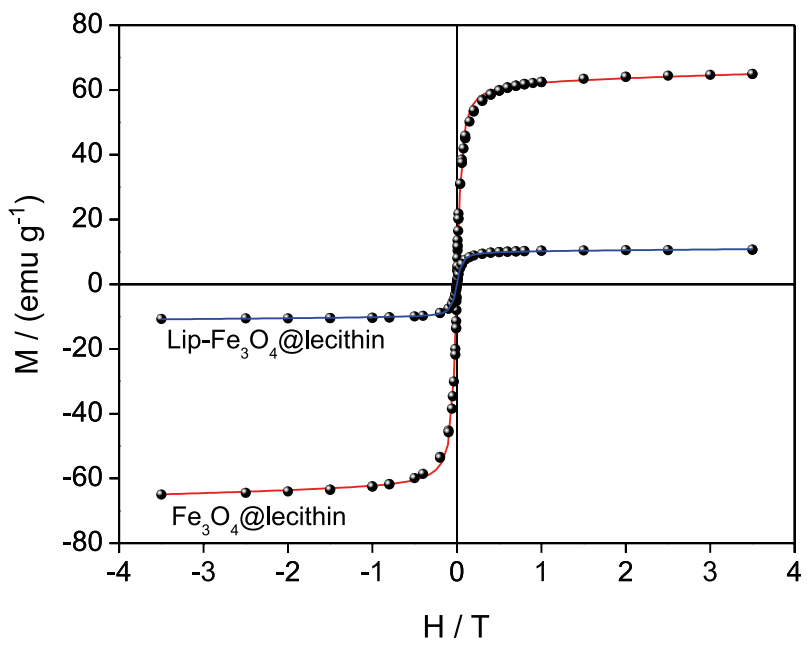

Figure 4. Hysteresis curve of $\mathrm{Fe}_{3} \mathrm{O}_{4} @$ lecithin and Lip- $\mathrm{Fe}_{3} \mathrm{O}_{4} @$ lecithin at $310 \mathrm{~K}$.

were evaluated for 14 days (Table 3). Liposomes exhibited temporal stability in aqueous medium and PI compatible with pharmaceutical applications. The zeta potential of the liposomes shows high values without the tendency toward agglomeration corroborating with the observed stability. ${ }^{44,45}$ The $\mathrm{pH}$ of the liposome samples remained stable at $\mathrm{pH} 7.3 \pm 0.1$.

Figures $5 \mathrm{a}$ and $5 \mathrm{~b}$ show the overlap of lecithin spectra with Lip-Stigma (Figure 5a) and lecithin with stigmasterol (Figure $5 b$ ). The overlap of the FTIR spectrum of lecithin and Lip-Stigma (Figure 5a) shows characteristic bands of soy lecithin components: $1741 \mathrm{~cm}^{-1}$ (ester carbonyl); 1261 and $1044 \mathrm{~cm}^{-1}$ (P-O-R bonds); $1630 \mathrm{~cm}^{-1}(-\mathrm{C}=\mathrm{C}-$, linoleic acid). It was possible to observe that there were no changes in the spectra pattern due to autoclaving and ultrasound of the sample in the Lip-Stigma. The absence of new bands in the $1600-1800 \mathrm{~cm}^{-1}$ in relation to soy lecithin corroborates 
Table 3. Physico-chemical parameters of the liposomal formulations for 14 days, stored at $4{ }^{\circ} \mathrm{C}$

\begin{tabular}{lcccc}
\hline Liposomal formulation & Size / nm & $\mathrm{PI}^{\mathrm{a}}$ & $\zeta^{\mathrm{b}} / \mathrm{mV}$ & $\begin{array}{c}\text { Weight } \\
\text { loss }^{\mathrm{c}} / \%\end{array}$ \\
\hline Lip & $189 \pm 4$ & 0.325 & $-41 \pm 1$ & - \\
Lip-Stigma & $160 \pm 4$ & 0.250 & $-49 \pm 1$ & - \\
Lip-Fe $\mathrm{O}_{4} @$ lecithin & $142 \pm 4$ & 0.198 & $-53 \pm 1$ & 5 \\
Lip-Stigma-Fe $\mathrm{O}_{4} @$ lecithin & $146 \pm 4$ & 0.230 & $-69 \pm 3$ & 5 \\
\hline
\end{tabular}

a Polydispersity index deviations less than $3 \%$ in the period; ${ }^{\text {bzeta potential; }}$ closs of mass corresponding to $\mathrm{Fe}_{3} \mathrm{O}_{4}$ for 14 days.

with the observation of absence of free fatty acids, due to the process of the autoclaving and sonication in the Lip and Lip-Stigma ${ }^{46-48}$ Comparison of the soy lecithin sample with the stigmasterol pattern (Figure 5b) shows an overlap of the stigmasterol bands with the soy lecithin bands. This
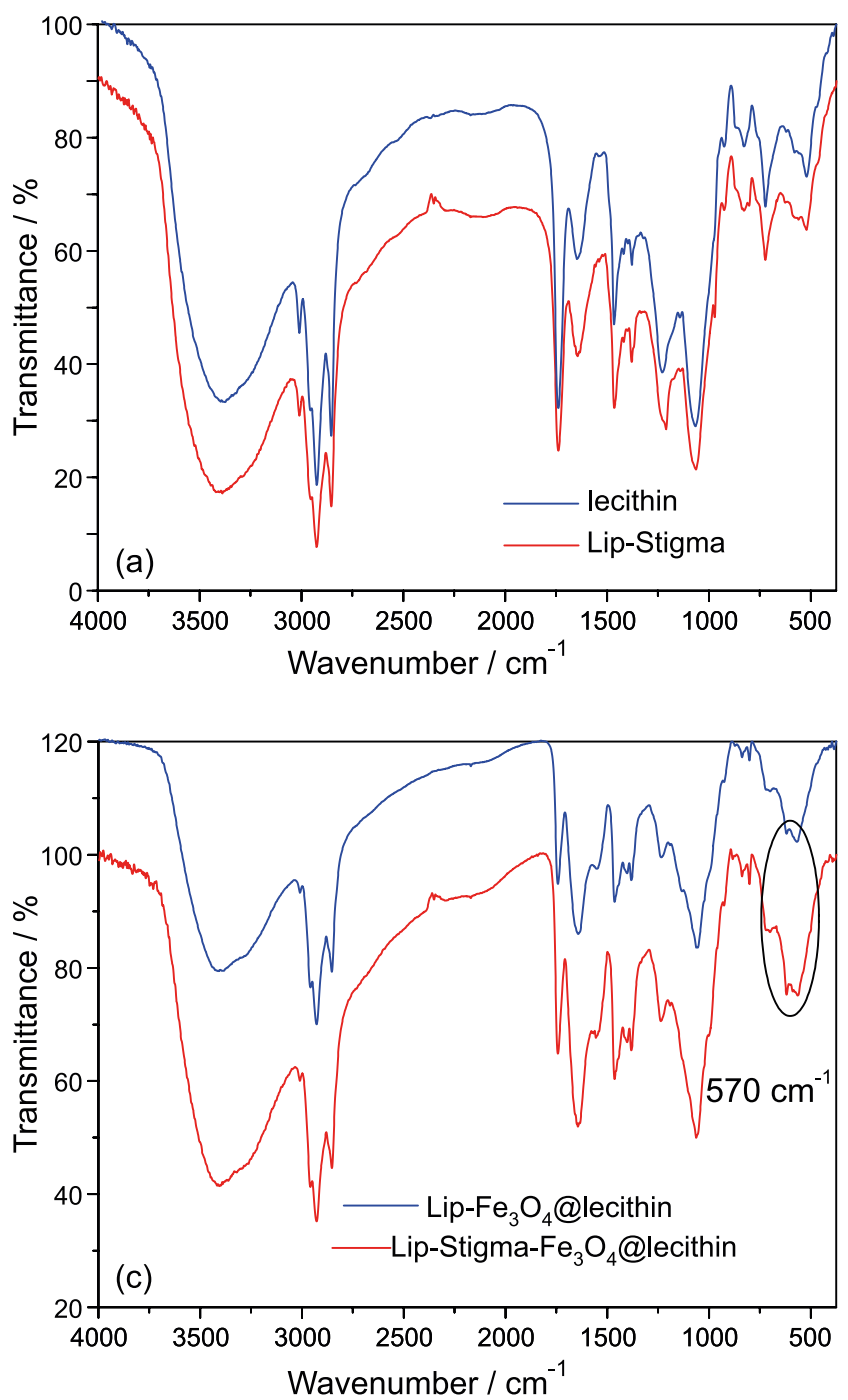

can be explained by the presence of steroids in the initial lecithin sample hindering the detection of stigmasterol. The band at $570 \mathrm{~cm}^{-1}$ (Figures $5 \mathrm{c}$ and $5 \mathrm{~d}$ ) confirms the presence of the $\mathrm{Fe}-\mathrm{O}$ bond of the magnetite phase showing that the NPs coating coverage was efficient in maintaining the magnetite as the only phase. ${ }^{49-53}$ The comparison of Lip- $\mathrm{Fe}_{3} \mathrm{O}_{4} @$ lecithin and $\mathrm{Fe}_{3} \mathrm{O}_{4} @$ lecithin spectra (Figure 3) reveals the intensification of the bands pertaining to lecithin due to the encapsulation of $\mathrm{Fe}_{3} \mathrm{O}_{4} @$ lecithin.

The TEM image and EFTEM maps ${ }^{54}$ of C coated (of soy lecithin) (Figures 6a and 6b) of Lip- $\mathrm{Fe}_{3} \mathrm{O}_{4} @$ lecithin show a dense population of NPs surrounded by phospholipids. The carbon of phospholipids on the surface of NPs were differentiated by energies lines. HRTEM images of Lip- $\mathrm{Fe}_{3} \mathrm{O}_{4} @$ lecithin (Figure 7) confirm a population of NPs surrounded by phospholipids. The surface coating of $\mathrm{Fe}_{3} \mathrm{O}_{4} \mathrm{NPs}$ with lecithin in the $\mathrm{Fe}_{3} \mathrm{O}_{4} @$ lecithin sample favored
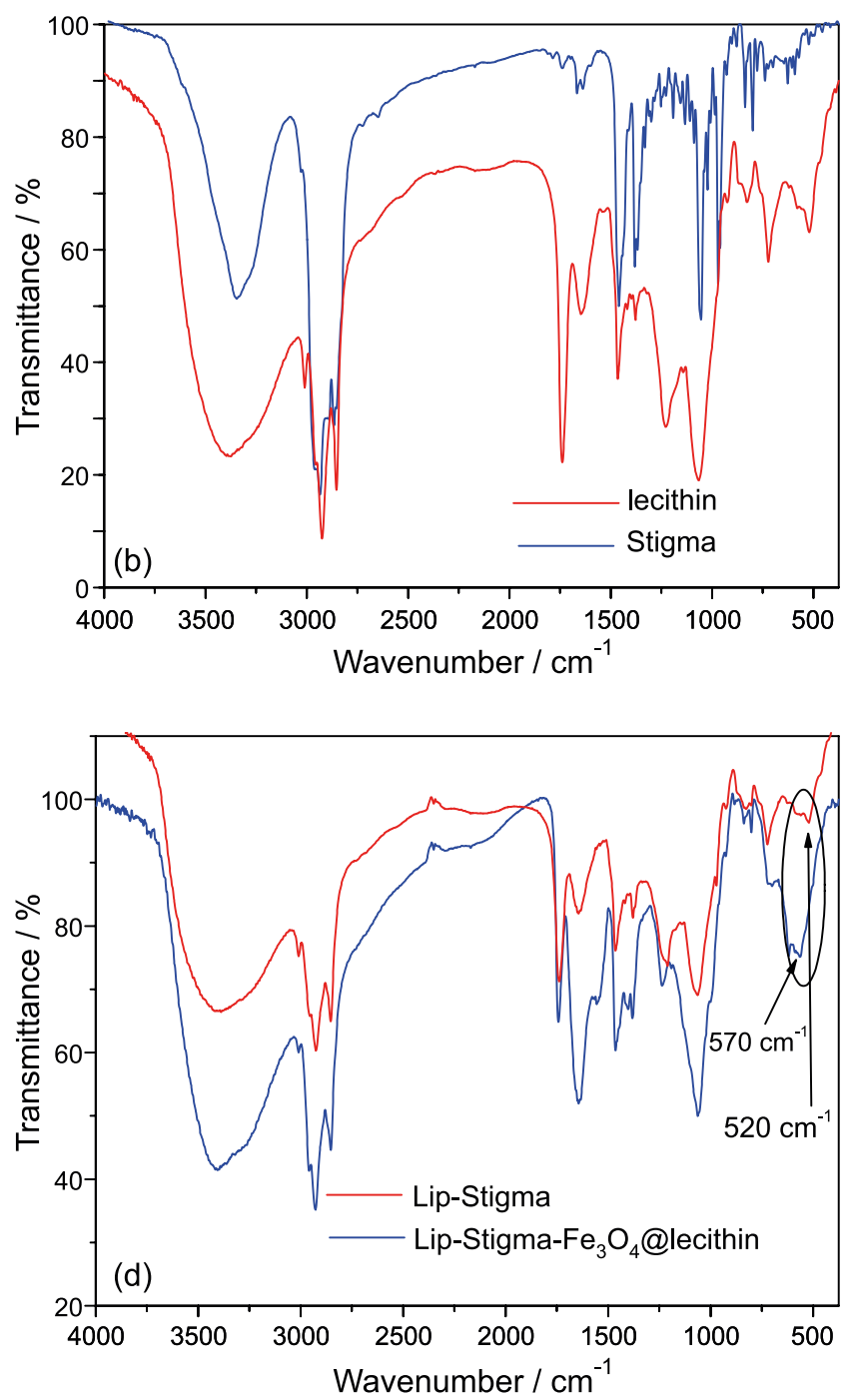

Figure 5. FTIR spectra of (a) Lip-Stigma and soy lecithin; (b) stigmasterol (Stigma) and soy lecithin; (c) Lip- $\mathrm{Fe}_{3} \mathrm{O}_{4} @$ lecithin, Lip-Stigma-Fe $\mathrm{O}_{4} @$ lecithin; and (d) Lip-Stigma and Lip-Stigma- $\mathrm{Fe}_{3} \mathrm{O}_{4} @$ lecithin after 14 days at $4{ }^{\circ} \mathrm{C}$. 
the increase of the interactions of NPs with liposomes. It was observed that the coating facilitated the entry of NPs into the vesicles and reduced the ultrasound time duration. The reduced ultrasound time duration minimized the risks of oxidation of NPs and hydrolysis of phospholipids esters.

HRTEM images of the Lip- $\mathrm{Fe}_{3} \mathrm{O}_{4} @$ lecithin was used for the determination of the interplanar spacing and mean size of $\mathrm{Fe}_{3} \mathrm{O}_{4}$. The values of interplanar spacing found were consistent with magnetite (JCPDS 19-0629) described in Table 4. The values found are in agreement with the XRPD technique (Figure 2). However, in the XRPD spectra of Lip- $\mathrm{Fe}_{3} \mathrm{O}_{4} @$ lecithin and Lip-Stigma- $\mathrm{Fe}_{3} \mathrm{O}_{4} @$ lecithin, one can observe lower intensity of magnetite peaks due to the presence of soybean lecithin (amorphous) and it is also possible to observe peaks attributed to stigmasterol (JCPDS 10-638). The HRTEM technique enabled nanoscale analysis and the reduction of interferences observed in the XRPD spectrum due to the increase in the amount of soy lecithin and stigmasterol. Therefore, the results found by the two techniques enabled the confirmation of the maintenance of the magnetite phase in the liposomal samples.

Hysteresis curve of the Lip- $\mathrm{Fe}_{3} \mathrm{O}_{4} @$ lecithin (Figure 4) shows super paramagnetic behavior with values of saturation magnetization of $\mathrm{Ms}=10.3 \mathrm{emu} \mathrm{\textrm {g } ^ { - 1 }}$, magnetic moment of $\mu=1.87 \times 10^{-19} \mathrm{~J} \mathrm{~T}^{-1}$ and linear susceptibility of $\chi=0.2 \times 10^{-4} \mathrm{emu} \mathrm{g}^{-1}$ at $310 \mathrm{~K}$. The coercivity and remanent magnetization values were the same as for $\mathrm{Fe}_{3} \mathrm{O}_{4} @$ lecithin with values close to zero, corroborating the literature. ${ }^{53}$ The liposome size, zeta potential ( $\zeta), \mathrm{pH}$ and characterization by FTIR, HRTEM, EFTEM/electron energy loss spectroscopy (EELS) and magnetics measurements show promising stability for suitable pharmaceutical. ${ }^{55}$

The use of soy lecithin as the encapsulating agent offers advantages of commercial availability, low-cost, high encapsulation capacity, high zeta potential and physicochemical stability. The usual components described in the literature are phospholipids (PL) and steroids (S). ${ }^{56,57}$ The ${ }^{1} \mathrm{H}$ NMR was used for the determination of molar ratio
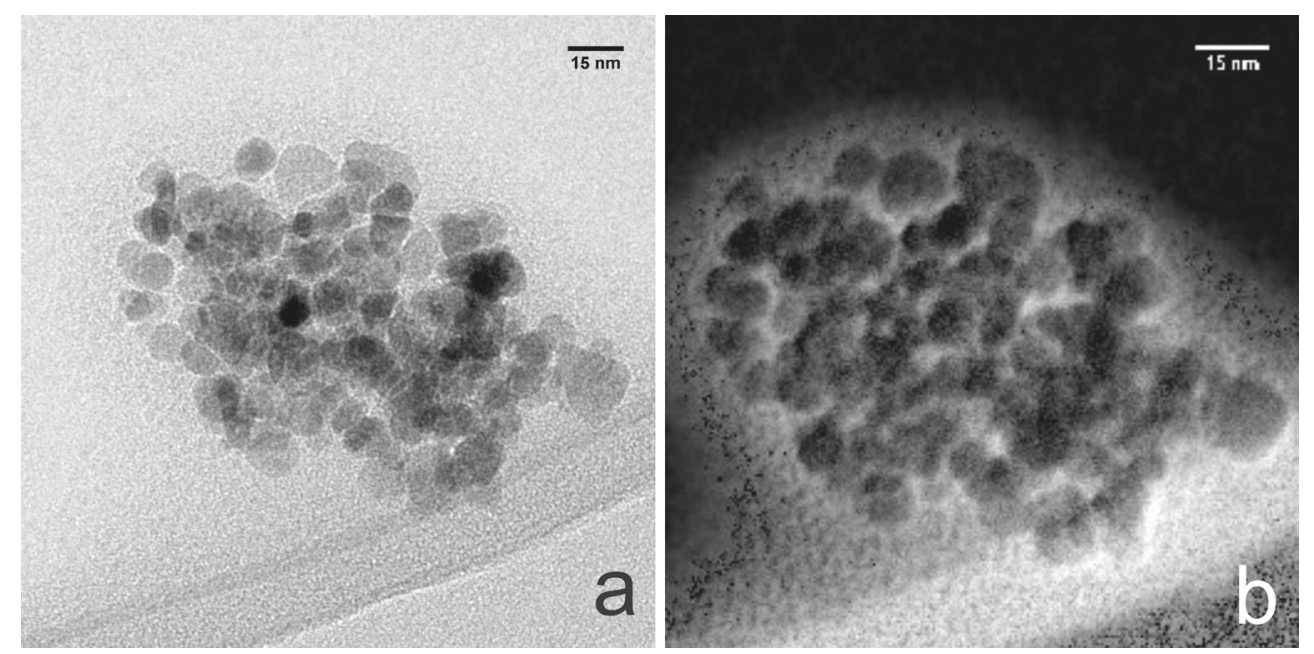

Figure 6. TEM image (a) and EFTEM maps (b) of $\mathrm{Lip}-\mathrm{Fe}_{3} \mathrm{O}_{4} @$ lecithin.

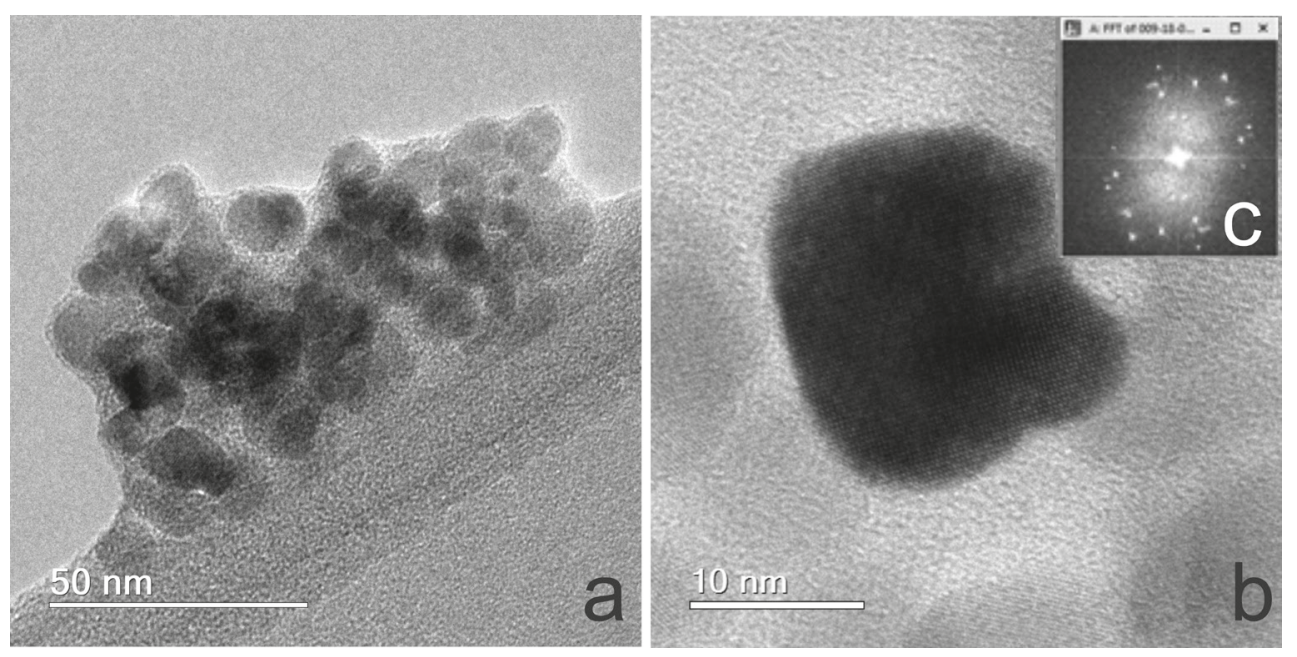

Figure 7. HRTEM images (a, b) and calculated FFT (c) of Lip- $-\mathrm{Fe}_{3} \mathrm{O}_{4} @$ lecithin. 
Table 4. Interplanar spacing of Lip- $\mathrm{Fe}_{3} \mathrm{O}_{4} @$ lecithin by fast Fourier transform (FFT)

\begin{tabular}{lcccc}
\hline Plane & $\mathrm{d} / \mathrm{nm}^{-1}$ & $1 / \mathrm{d} / \mathrm{nm}$ & Theoretical $/ \mathrm{nm}$ & Deviation $/ \%$ \\
\hline 533 & 7.841 & 0.1275 & 0.1281 & 0.4 \\
220 & 4.164 & 0.2402 & 0.2420 & 0.7 \\
622 & 7.944 & 0.1259 & 0.1266 & 0.6 \\
440 & 6.787 & 0.1473 & 0.1485 & 0.8 \\
440 & 6.729 & 0.1486 & 0.1485 & 0.1 \\
800 & 9.528 & 0.1050 & 0.1050 & 0 \\
\hline
\end{tabular}

d: interplanar spacing.

of the phospholipids and steroids in the Lip and Lip-Stigma samples (Figure S2, SI section). The signals observed in the soy lecithin sample prior to autoclaving/sonication and Lip coincide with the composition expected in the literature. ${ }^{57}$ The molar ratio of phospholipids and steroids found in the Lip and Lip-Stigma samples were 15:1 and 13:10 (PL:S), respectively. The technique also shows absence of new signals or significant difference was not observed between the soy lecithin and Lip spectra signals after 14 days. The absence of new signals indicates the absence of free fatty acids or oxidation due to the liposome formation. ${ }^{1} \mathrm{H}$ NMR and FTIR corroborate to show the efficiency of the methodologies used to prepare and to store the liposomes.

The inhibition of microbial growth at $24 \mathrm{~h}$ was shown in Figure 8. The strains S. aureus and C. freundii were sensitive to the liposomal formulations studied under all conditions. The WMF41 condition was established to evaluate the effect of temperature without the presence of a magnetic field in the antibacterial activity. Comparing the three conditions: WMF25, WMF41 and MF41, it can be seen that the elevation of temperature without the presence of the magnetic field increased bacterial growth. This occurrence was also observed in the study of Pseudomonas biofilms by
Park et al..$^{58}$ Kim et al..$^{59}$ also observed increased antibacterial activity due to the presence of the magnetic field in the study with $S$. aureus. The most efficient condition for inhibiting growth of the microorganisms was MF41, achieving inhibitions of up to $98 \%$ of the S. aureus colonies for the Lip- $\mathrm{Fe}_{3} \mathrm{O}_{4} @$ lecithin1. The specific absorption rate (SAR) calculated for samples Lip-Stigma- $\mathrm{Fe}_{3} \mathrm{O}_{4} @$ lecithin1 and Lip- $\mathrm{Fe}_{3} \mathrm{O}_{4} @$ lecithin1 were 1056 and $978 \mathrm{~W} \mathrm{~g}^{-1}$ of iron, respectively. ${ }^{60}$ The presence of stigmasterol increased the encapsulation capacity of NPs of the liposomes and the response of the NPs to the magnetic field (Figure S3, SI section). All samples presented excellent temperature responses in the presence of magnetic field (Figure S3, SI section)..$_{3,59,61}$ The limitation of temperature to $41 \pm 1{ }^{\circ} \mathrm{C}$ was used based upon literature references to avoid damage to healthy human cells. ${ }^{62}$ The evaluation of LipStigma1 in the MF41 condition shows that the stigma was active as antibacterial with inhibition of $92 \%$ of colonies. Traditional liposomes are accompanied by cholesterol as a steroid responsible for the control of drug release. ${ }^{28,29} \mathrm{We}$ decided to use stigmasterol because it is an abundant vegetable steroid which are proven to have biological activities. ${ }^{63,64}$ These excellent responses in the presence of magnetic field prompted us to try dilution of the liposomes for determination of minimum inhibitory concentration (MIC) in the MF41 condition. The results were: Lip-Stigma 2 demonstrated inhibition of $55 \%$ of C. freundii and $50 \%$ of $S$. aureus representing the most promising response for inhibition of $C$. freundii. The new dilutions resulted in the MIC of Lip- $\mathrm{Fe}_{3} \mathrm{O}_{4} @$ lecithin2 against $S$. aureus $\left(8.4 \mu \mathrm{g} \mathrm{mL}^{-1}\right.$ of magnetite) and inhibition of $49 \%$ of $C$. freundii colonies in the MF41 condition. This work was the first to evaluate the activity of NPs against C. freundii. The evaluation of the literature on $\mathrm{Fe}_{3} \mathrm{O}_{4}$ activity in relation to $S$. aureus showed a variety of methodologies

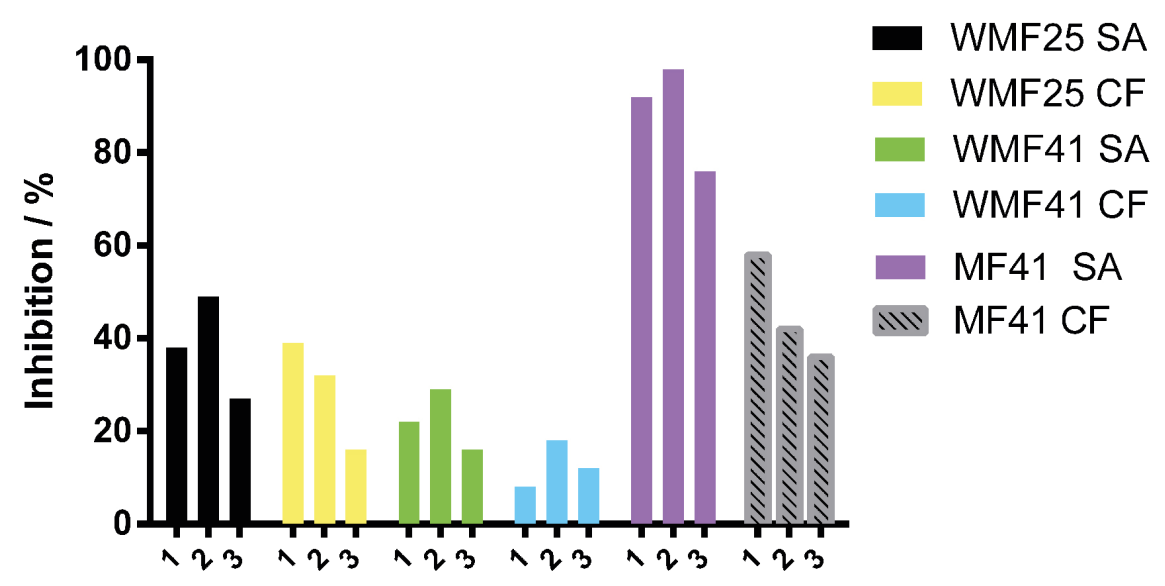

Figure 8. Antibacterial activity of liposomes: (1) Lip-Stigma; (2) Lip- $\mathrm{Fe}_{3} \mathrm{O}_{4} @$ lecithin; (3) Lip-Stigma- $\mathrm{Fe}_{3} \mathrm{O}_{4} @$ lecithin under conditions: without magnetic field at room temperature (WMF25); without magnetic field and $30 \mathrm{~min}$ at $41 \pm 1{ }^{\circ} \mathrm{C}$ (WMF 41) and with magnetic field at $41 \pm 1{ }^{\circ} \mathrm{C}$ (MF41) against S. aureus (SA) and C. freundii (CF). 
and results. ${ }^{14,16,19,20,65,66}$ In our work, the broth microdilution method using $\mathrm{UV}^{67}$ was initially tested, however, the results were not reproducible. Alternatively, the use of the agar dilution method ${ }^{39}$ proved to be more reliable and reproducible. A prior evaluation of the literature data shows that the nature of the coating was determinant in the activity's result. In the literature consulted, the best result described without a magnetic field was $47 \mu \mathrm{g} \mathrm{mL}{ }^{-1} .{ }^{16}$ When compared to our work, we observed that the encapsulating of $\mathrm{Fe}_{3} \mathrm{O}_{4} @$ lecithin into liposomes and the application of a magnetic field reduced the dosage required for MIC by approximately 6-fold.

\section{Conclusions}

In summary, this work resulted in an enhanced methodology for preparation of magnetoliposomes in terms of time, scalability and cost. Contrary to the liposomes conventional preparation, which uses toxic organic solvents, the methodology applied in this work does not use organic solvents. Additionally, the new process led to low risk of microbial contamination due to sterilization effect resulting from the autoclave step, inherent to the methodology. Liposomes prepared with soy lecithin show stability of physicochemical properties (liposome size, temporal stability, polydispersity index, zeta potential) and excellent magnetic response in vitro (SAR of $1056 \mathrm{~W} \mathrm{~g}^{-1}$ ) allowing a wide range of biomedical applications for treatments of multi-resistant microorganisms in the presence of magnetic field.

\section{Supplementary Information}

Supplementary data are available free of charge at http://jbcs.sbq.org.br as PDF file.

\section{Acknowledgments}

The authors would like to thank all the many UFMG employees who participated in this work; the employees of the microscopy center of the UFMG for the special attention; colleagues Wallace Doti do Pim for reading the paper; Denio Guimarães Takahashi for the graphical abstract art; Luciano R. Lara that was essential for this work; the funding agencies Capes, CNPQ and FAPEMIG for the financing.

\section{References}

1. Hasan, R.; Acharjee, M.; Noor, R.; Tzu Chi Med. J. 2016, 28, 49.
2. Munita, J. M.; Arias, C. A.; Microbiol. Spectrum 2016, 4, VMBF-0016-2015.

3. Ruppé, É.; Woerther, P.-L.; Barbier, F.; Ann. Intensive Care 2015, 5, 21.

4. Holban, A. M.; Curr. Top. Med. Chem. 2015, 15, 1589.

5. Hiramatsu, K.; Katayama, Y.; Matsuo, M.; Sasaki, T.; Morimoto, Y.; Sekiguchi, A.; Baba, T.; J. Infect. Chemother. 2014, 20, 593.

6. World Health Organization (WHO); Global Priority List of Antibiotic-Resistant Bacteria to Guide Research, Discovery, and Development of New Antibiotics; WHO: Geneva, Switzerland, 2017.

7. Liu, L.-H.; Wang, N.-Y.; Wu, A. Y.-J.; Lin, C.-C.; Lee, C.-M.; Liu, C.-P.; J. Microbiol., Immunol. Infect. 2018, 51, 565.

8. Pelgrift, R. Y.; Friedman, A. J.; Adv. Drug Delivery Rev. 2013, 65, 1803.

9. Lara, L. R. S.; Zottis, A. D.; Elias, W. C.; Faggion, D.; de Campos, C. E. M.; Acuna, J. J. S.; Domingos, J. B.; RSC Adv. 2015, 5, 8289 .

10. Andrade, Â. L.; Valente, M. A.; Ferreira, J. M. F.; Fabris, J. D.; J. Magn. Magn. Mater. 2012, 324, 1753.

11. German, S. V.; Navolokin, N. A.; Kuznetsova, N. R.; Zuev, V. V.; Inozemtseva, O. A.; Anis'kov, A. A.; Volkova, E. K.; Bucharskaya, A. B.; Maslyakova, G. N.; Fakhrullin, R. F.; Terentyuk, G. S.; Vodovozova, E. L.; Gorin, D. A.; Colloids Surf., B 2015, 135 (Supplement C), 109.

12. Marciello, M.; Connord, V.; Veintemillas-Verdaguer, S.; Verges, M. A.; Carrey, J.; Respaud, M.; Serna, C. J.; Morales, M. P.; J. Mater. Chem. B 2013, 1, 5995.

13. Petcharoen, K.; Sirivat, A.; Mater. Sci. Eng., B 2012, 177, 421.

14. Darwish, M. S.; Nguyen, N. H.; Ševců, A.; Stibor, I.; Smoukov, S. K.; Mater. Sci. Eng., C 2016, 63, 88.

15. Prabhu, Y. T.; Rao, K. V.; Kumari, B. S.; Kumar, V. S. S.; Pavani, T.; Int. Nano Lett. 2015, 5, 85.

16. Ramteke, C.; Ketan Sarangi, B.; Chakrabarti, T.; Mudliar, S.; Satpute, D.; Avatar Pandey, R.; Curr. Nanosci. 2010, 6, 587.

17. Shariatinia, Z.; Nikfar, Z.; Int. J. Biol. Macromol. 2013, 60 (Supplement C), 226.

18. Ferreira, R. V.; Martins, T. M. M.; Goes, A. M.; Fabris, J. D.; Cavalcante, L. C. D.; Outon, L. E. F.; Domingues, R. Z.; Nanotechnology 2016, 27, 085105.

19. Hsieh, S.; Huang, B. Y.; Hsieh, S. L.; Wu, C. C.; Wu, C. H.; Lin, P. Y.; Huang, Y. S.; Chang, C. W.; Nanotechnology 2010 , $21,445601$.

20. Inbaraj, B. S.; Kao, T.; Tsai, T.; Chiu, C.; Kumar, R.; Chen, B.-H.; Nanotechnology 2011, 22, 075101.

21. Nappini, S.; Fogli, S.; Castroflorio, B.; Bonini, M.; Baldelli Bombelli, F.; Baglioni, P.; J. Mater. Chem. B 2016, 4, 716.

22. Drulis-Kawa, Z.; Dorotkiewicz-Jach, A.; Int. J. Pharm. 2010, 387, 187.

23. Li, T.; Deng, Y.; Song, X.; Jin, Z.; Zhang, Y.; Bull. Korean Chem. Soc. 2003, 24, 957. 
24. Hosseini, F.; Sadjadi, M. S.; Orient. J. Chem. 2016, 32, 2901.

25. Latifi, S.; Tamayol, A.; Habibey, R.; Sabzevari, R.; Kahn, C.; Geny, D.; Eftekharpour, E.; Annabi, N.; Blau, A.; Linder, M.; Arab-Tehrany, E.; Sci. Rep. 2016, 6, 25777.

26. Carugo, D.; Bottaro, E.; Owen, J.; Stride, E.; Nastruzzi, C.; Sci. Rep. 2016, 6, 25876.

27. Woodbury, D. J.; Richardson, E. S.; Grigg, A. W.; Welling, R. D.; Knudson, B. H.; J. Liposome Res. 2006, 16, 57.

28. Frézard, F.; Silva-Barcellos, N. M.; dos Santos, R. A.; Regul. Pept. 2007, 138, 59.

29. Kikuchi, H.; Carlsson, A.; Yachi, K.; Hirota, S.; Chem. Pharm. Bull. 1991, 39, 1018.

30. Akbarzadeh, A.; Rezaei-Sadabady, R.; Davaran, S.; Joo, S. W.; Zarghami, N.; Hanifehpour, Y.; Samiei, M.; Kouhi, M.; NejatiKoshki, K.; Nanoscale Res. Lett. 2013, 8, 102.

31. Abareshi, M.; Goharshadi, E. K.; Mojtaba Zebarjad, S.; Khandan Fadafan, H.; Youssefi, A.; J. Magn. Magn. Mater. 2010, 322, 3895.

32. Ma, K.; Zhao, H.; Zheng, X.; Sun, H.; Hu, L.; Zhu, L.; Shen, Y.; Luo, T.; Dai, H.; Wang, J.; J. Mater. Chem. B 2017, 5, 2888.

33. Chen, Y.; Qian, Z.; Zhang, Z.; Colloids Surf., A 2008, 312, 209.

34. Ong, S. G. M.; Ming, L. C.; Lee, K. S.; Yuen, K. H.; Pharmaceutics 2016, 8, 25.

35. Reichel, V.; Kovács, A.; Kumari, M.; Bereczk-Tompa, É.; Schneck, E.; Diehle, P.; Pósfai, M.; Hirt, A. M.; Duchamp, M.; Dunin-Borkowski, R. E.; Sci. Rep. 2017, 7, 45484.

36. Fischer, A.; Schmitz, M.; Aichmayer, B.; Fratzl, P.; Faivre, D.; J. R. Soc., Interface 2011, 8, 1011.

37. Bozzola, J. J.; Russell, L. D.; Electron Microscopy: Principles and Techniques for Biologists; Jones \& Bartlett Learning: Boston, 1999.

38. Golla-Schindler, U.; Hinrichs, R.; Bomati-Miguel, O.; Putnis, A.; Micron 2006, 37, 473.

39. Wiegand, I.; Hilpert, K.; Hancock, R. E.; Nat. Protoc. 2008, 3, 163.

40. Harifi, T.; Montazer, M.; J. Mater. Chem. B 2014, 2, 272.

41. El Ghandoor, H.; Zidan, H.; Khalil, M. M.; Ismail, M.; Int. J. Electrochem. Sci. 2012, 7, 5734.

42. Liu, X. L.; Choo, E. S. G.; Ahmed, A. S.; Zhao, L. Y.; Yang, Y.; Ramanujan, R. V.; Xue, J. M.; Di Fan, D.; Fan, H. M.; Ding, J.; J. Mater. Chem. B 2014, 2, 120.

43. Lan, N. T.; Duong, N. P.; Hien, T. D.; J. Alloys Compd. 2011, 509, 5919.

44. Chen, Y.; Liu, J.; Angelov, B.; Drechsler, M.; Garamus, V. M.; Willumeit-Römer, R.; Zou, A.; Colloids Surf., B 2016, 140, 74.

45. Zhao, L.; Temelli, F.; Curtis, J. M.; Chen, L.; Food Res. Int. 2015, 77, 63 .

46. Abramson, M. B.; Norton, W. T.; Katzman, R.; J. Biol. Chem. 1965, 240, 2389.

47. Fookson, J. E.; Wallach, D. F.; Arch. Biochem. Biophys. 1978, 189, 195.
48. Kim, M.-J.; Jang, D.-H.; Kim, H.-K.; Lee, Y.-I.; Lee, G.-J.; Yoo, B.-Y.; Choa, Y.-H.; J. Nanosci. Nanotechnol. 2011, 11, 4592.

49. Jubb, A. M.; Allen, H. C.; ACS Appl. Mater. Interfaces 2010, 2, 2804.

50. Li, Y.-S.; Church, J. S.; Woodhead, A. L.; J. Magn. Magn. Mater. 2012, 324, 1543.

51. Liese, H.; Am. Mineral. 1967, 52, 1198.

52. Millan, A.; Palacio, F.; Falqui, A.; Snoeck, E.; Serin, V.; Bhattacharjee, A.; Ksenofontov, V.; Gütlich, P.; Gilbert, I.; Acta Mater. 2007, 55, 2201.

53. Sadhukha, T.; Wiedmann, T. S.; Panyam, J.; Biomaterials 2014, 35,7860 .

54. Anjum, D. H.; Memon, N. K.; Ismail, M.; Hedhili, M. N.; Sharif, U.; Chung, S. H.; Nanotechnology 2016, 27, 365709.

55. Kraft, J. C.; Freeling, J. P.; Wang, Z.; Ho, R. J.; J. Pharm. Sci. 2014, 103, 29.

56. Mertins, O.; Sebben, M.; Schneider, P. H.; Pohlmann, A. R.; Silveira, N. P.; Quim. Nova 2008, 31, 1856.

57. Scholfield, C.; J. Am. Oil Chem. Soc. 1981, 58, 889.

58. Park, H.; Park, H.-J.; Kim, J. A.; Lee, S. H.; Kim, J. H.; Yoon, J.; Park, T. H.; J. Microbiol. Methods 2011, 84, 41.

59. Kim, M.-H.; Yamayoshi, I.; Mathew, S.; Lin, H.; Nayfach, J.; Simon, S. I.; Ann. Biomed. Eng. 2013, 41, 598.

60. Di Corato, R.; Espinosa, A.; Lartigue, L.; Tharaud, M.; Chat, S.; Pellegrino, T.; Ménager, C.; Gazeau, F.; Wilhelm, C.; Biomaterials 2014, 35, 6400.

61. Subbiahdoss, G.; Sharifi, S.; Grijpma, D. W.; Laurent, S.; van der Mei, H. C.; Mahmoudi, M.; Busscher, H. J.; Acta Biomater. 2012, 8, 2047.

62. Yoshida, M.; Sato, M.; Yamamoto, Y.; Maehara, T.; Naohara, T.; Aono, H.; Sugishita, H.; Sato, K.; Watanabe, Y.; J. Gastroenterol. Hepatol. 2012, 27, 406.

63. Bhatti, H. N.; Khera, R. A.; Steroids 2012, 77, 1267.

64. Gabay, O.; Sanchez, C.; Salvat, C.; Chevy, F.; Breton, M.; Nourissat, G.; Wolf, C.; Jacques, C.; Berenbaum, F.; Osteoarthr. Cartilage 2010, 18, 106.

65. Darwish, M. S.; Nguyen, N. H.; Ševců, A.; Stibor, I.; J. Nanomater. 2015, 16, 10.

66. Grumezescu, A. M.; Cristescu, R.; Chifiriuc, M.; Dorcioman, G.; Socol, G.; Mihailescu, I.; Mihaiescu, D. E.; Ficai, A.; Vasile, O.; Enculescu, M.; Biofabrication 2015, 7, 015014.

67. Sousa, G. F.; Aguilar, M. G.; Dias, D. F.; Takahashi, J. A.; Moreira, M. E. C.; Vieira Filho, S. A.; Silva, G. D. F.; Rodrigues, S. B. V.; Messias, M. C. T. B.; Duarte, L. P.; Phytochem. Lett. 2017, 21 (Supplement C), 61.

Submitted: April 10, 2018 Published online: July 30, 2018 